\title{
PATRICIO ZAPATA ORMEÑO, \\ SEMBLANZA DE UN MAESTRO
}

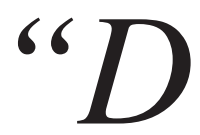

espacito y buena letra, que el hacer las cosas bien importa más que el hacerlas". Este viejoaforismo cervantino expresa la médula de aquello que, los que tuvimos el privilegio de formarnos con Patricio Zapata, aprendimos de su disciplinada y rigurosa forma de trabajar.

La meticulosa preparación de los experimentos, la concentración durante el curso de su realización, la grabación magnetofónica de los registros electrofisiológicos, la redacción en inglés del protocolo experimental, el análisis y graficación de resultados, la revisión actualizada de la literatura científica, la larga sucesión de borradores implacablemente corregidos con rojo, la preparación de fotografías, tablas, gráficos e ilustraciones, la preparación esmerada de las presentaciones a Congreso. Cada una de estas etapas, una y otra vez repetidas, fueron forjando en cada uno de nosotros una suerte de 'segunda naturaleza' que ha dejado una huella indeleble en nuestra vida personal y profesional.

¿Cómo no recordar, además, el clima humano del laboratorio, que en contraste con lo que ocurría en el mundo exterior, invitaba a concentrarse y trabajar? En ese ambiente, marcado por el trabajo y el estudio, la seriedad, el respeto y la cortesía, no estaban ausentes el comentario culto, la gracia, el humor y la visión positiva de las cosas. Estas últimas características, fruto sobre todo de la eficiencia y de la calidad humana de la señora Carolina Larraín, que en sus múltiples funciones de dactilógrafa, secretaria ejecutiva, científica, technician, dibujante técnica, enfermera, editora asistente y relacionadora pública, permitía desarticular a tiempo muchas de las

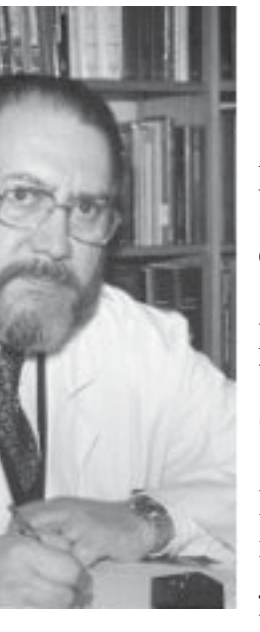

potenciales interrupciones que suelen entorpecer la labor científica.

Durante sus estudios de Medicina en la Pontificia Universidad Católica de Chile (1956-1963), Patricio Zapata se aficionó tempranamente a la investigación bajo la influencia de profesores como Juan de Dios Vial Correa, Héctor Croxatto y Joaquín

Luco.

A Carlos Eyzaguirre, que venía de publicar los influyentes trabajos de inhibición postsináptica con Stephen Kuffler (2, 3, 13), lo tuvo temprana e incidentalmente como profesor, y mantendría con él una correspondencia que lo tuvo al tanto de las publicaciones que este generaba en los EE.UU.; en particular aquellas sobre receptores musculares intrafusales (4-6) y las primeras sobre quimiorreceptores arteriales realizadas con la colaboración de Lewin $(7,8)$ y Koyano (9). La actualidad de las investigaciones que reportaba Eyzaguirre lo fascinaba.

Su primera estadía en la Universidad de Utah en Salt Lake City entre 1965 y 1967 culmina con sus dos primeras publicaciones con Carlos Eyzaguirre en el prestigioso Journal of Physiology de Londres $(10,11)$, revista altamente exigente en la cual publicaría posteriormente otros cuatro artículos $(12,14,15,17)$, de todos los cuales guardará un grato y la vez que doloroso recuerdo. Esas experiencias de intensa interacción formativa con su mentor y con los editores científicos de las publicaciones más exigentes serán probablemente su mejor escuela de rigurosidad y perseverancia.

De vuelta en Chile, en plena época de la Reforma Universitaria, ejercerá por 
períodos la jefatura del Laboratorio de Neurofisiología y luego del recién creado Departamento de Neurobiología. En esa época publica, junto a Jaime Álvarez, su único trabajo científico conjunto (1) y mantendrá con él una larga historia de amistad y de colaboración docente en el prestigiado Curso de Fisiología General y Neurofisiología para la carrera de Medicina (18). De esa época es también su trabajo sobre unidades mecanorreceptoras del nervio hipogloso con Gonzalo Torrealba (16).

En 1973 regresa nuevamente por dos años a la Universidad de Utah en la segunda de sus tres estadías en esa Universidad. Profesor Titular de la Facultad de Ciencias Biológicas en 1973 y de la Facultad de Medicina en 1977. Ejercerá como jefe del Laboratorio de Neurobiología del Departamento de Ciencias Fisiológicas en la Facultad de Ciencias Biológicas de la P. Universidad Católica de Chile desde 1977. En ese laboratorio se formarán con él una larga serie de discípulos: Alfredo Zuazo, Hugo Cárdenas, Carlos Díaz, Alejandro Serani, Manuel Lavados, Julio Alcayaga, Rodrigo Iturriaga, Jaime Eugenín, Ricardo Fadic y R. Fernández, varios de los cuales lo tendrán como Director de sus Tesis de Doctorado.

Patricio Zapata hará un aporte decisivo al Programa de Doctorado en Ciencias Fisiológicas de su Universidad, del cual será Director entre 1983 y 1988, y entre 1993 y 2003, sumando un total de 15 años. Desde el año 1992 al 1998 le corresponderá además un papel protagónico en el plano científico nacional como primer Editor Jefe de la recién creada Biological Research, sucesora de los Archivos de Biología y Medicina Experimentales. Junto a la Editora Asociada, su esposa y colaboradora Carolina Larraín, tendrán a su cargo la titánica tarea de reformulación de esa publicación científica que ocupa hoy en día un sitial de privilegio en el concierto iberoamericano $(19,20)$. De esa época conservará el recuerdo de un trabajo interesante, entretenido, pero a la vez agotador.

No estoy en condiciones de hacer una valoración del contenido mismo del trabajo científico de Patricio Zapata, el que además de ser copioso no está tampoco terminado. Lo que sí puedo modestamente intentar bosquejar, es su figura como persona, como hombre de ciencia y como formador.

Cuando joven yo también, a la sazón estudiante de Medicina en la Universidad de Chile, y fuertemente impresionado por la estatura científica y humana del profesor Bruno Günther Schaffeld, pensé en dedicar mi vida profesional a la ciencia, no me sentí ciertamente estimulado al escuchar la consabida frase que en la investigación científica el $1 \%$ es inspiración y el $99 \%$ transpiración. Así y todo, mi atracción por la ciencia era tal, que no dudé en seguir ese camino. Cuando en sexto año de Medicina llegué desde otra universidad a golpear la puerta del Laboratorio de Neurobiología de la P. Universidad Católica de Chile, pienso que traía en mis hábitos de trabajo un $90 \%$ de inspiración y a lo más $10 \%$ de transpiración. Estimo que no debe haber sido muy distinto para el resto de los que cruzamos el umbral del Laboratorio de Neurobiología para quedarnos ahí por un tiempo, y creo no equivocarme al decir que le debemos a Patricio Zapata haber podido equilibrar considerablemente $-y$ hasta invertir- en nuestros hábitos de trabajo esa relación de porcentajes. Esa transformación, sin embargo, no fue producto de un cambio meramente mecánico, sino de un proceso profundamente humano. Sin el ejemplo de estudio, de discusión seria, de amplia cultura biológica y médica, de generosidad en gastar su tiempo en escucharnos, corregirnos y soportarnos, difícilmente hubiésemos perseverado en esa ardua tarea.

Cada comunidad tiene sus tradiciones y sus valores que deben ser transmitidos de persona a persona, y la comunidad científica tiene los suyos. Algunos de ellos son: la responsabilidad de la comunicación honesta y completa de los resultados, el respeto y la consideración objetiva del trabajo de los demás, la solidaridad con los pares, la imparcialidad y la acuciosidad del juicio crítico. Cada uno de ellos y muchos otros los vimos encarnados en el día a día del trabajo junto a Patricio Zapata. Hoy que la vida pone sobre nuestros hombros análogas responsabilidades, y que tenemos 
nuestros propios alumnos a quienes escuchar, corregir y soportar, me sorprendo y alegro cuando me veo entregando a otros, ni más ni menos que lo gratuitamente y generosamente recibido de mi maestro.

\section{ALEJANDRO SERANI-MERLO}

Facultad de Medicina Universidad de los Andes, Santiago, Chile

\section{REFERENCIAS}

1. DONOSO A, ZAPATA P, ÁLVAREZ J (1970) Incorporation of tritiated choline by the carotid body incubated in vitro. Arch Biol Med Exp 7: 1-7

2. EYZAGUIRRE C, KUFFLER SW (1955) Processes of excitation in the dendrites and in the soma of single isolated sensory nerve cells of the lobster and crayfish. J Gen Physiol 39: 87-119

3. EYZAGUIRRE C, KUFFLER SW (1955) Further study of soma, dendrite, and axon excitation in single neurons. J Gen Physiol 39: 121-53

4. EYZAGUIRRE C, VIAL JD (1956) Electrical activity of the intrafusal muscle fibre. Nature 178: 317-318

5. EYZAGUIRRE C (1960) The electrical activity of mammalian intrafusal fibres. J Physiol 150: 169-185

6. EYZAGUIRRE C (1960) The motor regulation of mammalian spindle discharges. J Physiol 150: 186-200

7. EYZAGUIRRE C, LEWIN J (1961) Effect of different oxygen tensions on the carotid body in vitro. J Physiol (Paris) 159: 238-250

8. EYZAGUIRRE C, LEWIN J (1961) Chemoreceptor activity of the carotid body of the cat. J Physiol (Paris) 159: $222-237$
9. EYZAGUIRRE C, KOYANO H (1965) Effects of hypoxia, hypercapnia, and $\mathrm{pH}$ on the chemoreceptor activity of the carotid body in vitro. J Physiol 178: 385-409

10. EYZAGUIRRE C, ZAPATA P (1968) Pharmacology of $\mathrm{pH}$ effects on carotid body chemoreceptors in vitro. $\mathrm{J}$ Physiol (Lond) 195: 557-588

11. EYZAGUIRRE C, ZAPATA P (1968) The release of acetylcholine from carotid body tissues. Further study on the effects of acetylcholine and cholinergic blocking agents on the chemosensory discharge. J Physiol (Lond) 195: 589-607

12. EYZAGUIRRE C, FIDONE S, ZAPATA P (1972) Membrane potential changes recorded from the mucosa of the toad's tongue during chemical stimulation. J Physiol (Lond) 221: 515-532

13. KUFFLER SW, EYZAGUIRRE C (1955) Synaptic inhibition in an isolated nerve cell. J Gen Physiol 39: 155-84

14. LLADOS F, ZAPATA P (1978) Effects of dopamine analogues and antagonists on carotid body chemosensors in situ. J Physiol (Lond) 274: 487-499

15. LLADOS F, ZAPATA P (1978) Effects of adrenoceptor stimulating and blocking agents on carotid body chemosensory inhibition. J Physiol (Lond) 274: 501-509

16. ZAPATA P, TORREALBA G (1971) Mechanosensory units in the hypoglossal nerve of the cat. Brain Res 32: 349-367

17. ZAPATA P (1975) Effects of dopamine on carotid chemo- and baroreceptors in vitro. J Physiol (Lond) 244: $235-251$

18. ZAPATA P, ÁLVAREZ J (1979) Design of a physiology course in relation to medical education. Educ Méd Salud, Washington, D.C. 13: 134-147

19. ZAPATA P, LARRAÍN C (1995) A report on the evolution of this journal and an analysis of its present state and perspectives. Biol Res 27: 159-169

20. ZAPATA P (1999) Farewell from the Editor. Biol Res 31: $323-324$ 